\title{
Salmonella em carcaças de frango congeladas ${ }^{1}$
}

\author{
Débora Martins Silva Santos ${ }^{2}$, Angelo Berchieri Junior ${ }^{3}$, Suely Aparecida Fernandes ${ }^{4}$, \\ Ana Terezinha Tavechio ${ }^{4}$ e Luiz Augusto do Amaral ${ }^{5}$
}

\begin{abstract}
Santos D.M.S., Berchieri Jr A., Fernandes S.A., Tavechio A.T. \& Amaral L.A. 2000. [Salmonella in broiler frozen carcasses.] Salmonella em carcaças de frango congeladas. Pesquisa Veterinária Brasileira 20(1):39-42. Depto Patologia Veterinária, Fac. Ciências Agrárias e Veterinárias, Campus de Jaboticabal, Via de acesso Paulo Donato Castellane s/n, Jaboticabal, SP 14870-000, Brazil.

Hundred and fifty frozen broiler carcasses of four commercial brands, purchased at retail stores for Salmonella research, were examined: 43 of the carcasses referred to each of the brands A, B, D and 21 of brand C. Thirty-two percent of the samples were found positive; 11 serotypes were identified as $S$. Agona, $S$. Anatum, $S$. Enteritidis, $S$. Hadar, $S$. Havana, $S$. Mbandaka, S. Montevideo, S. Ouakam, S. Poona, S. Schwarzengrund and S.I4, 5, 12:-. Antibiogram testing of the isolated strains showed $100 \%$ resistance to ampicilin, $75.0 \%$ to cefhalotin, $52.1 \%$ to cephoxitin, $22.9 \%$ to tobramicin, $6.2 \%$ to polimixin B and to tetracyclines, $4.2 \%$ to gentamicin, and $2.1 \%$ to netilmicin, to aztreonam and to amicacin. All strains showed total sensibility to chloramphenicol and to sulfazotrim.
\end{abstract}

INDEX TERMS: Salmonella, retail, serotypes, broiler frozen, carcasses, antibiogram.

RESUMO.- Um total de 150 carcaças de frango congeladas, de quatro marcas comerciais, foram analisadas para pesquisa de Salmonella. Foram examinadas 43 carcaças de cada uma das marcas A, B, D e 21 da marca C. Observou-se um percentual de $32,0 \%$ de contaminação. Foram identificados 11 sorotipos: $S$. Agona, S. Anatum, S. Enteritidis, S. Hadar, S. Havana, $S$. Mbandaka, S. Montevideo, S. Ouakam, S. Poona, S. Schwarzengrund e $S$. I 4, 5, 12: -. O antibiograma das cepas mostrou $100 \%$ de resistência à ampicilina, $75,0 \%$ à cefalotina, $52,1 \%$ à cefoxitina, $22,9 \%$ à tobramicina, $6,2 \%$ à polimixina $\mathrm{B} e$ à tetraciclina, $4,2 \%$ à gentamicina e $2,1 \%$ à netilmicina, ao aztreonam e à amicacina. Todas as cepas apresentaram sensibilidade total ao cloranfenicol e ao sulfazotrim.

TERMOS DE INDEXAÇÃO: Salmonella, varejo, sorotipos, frango congelado, carcaças, antibiograma.

\footnotetext{
${ }^{1}$ Aceito para publicação em 23 de dezembro de 1999.

${ }^{2}$ Mestre em Medicina Veterinária Preventiva.

${ }^{3}$ Depto Patologia Veterinária, Faculdade de Ciências Agrárias e Veterinárias, Campus de Jaboticabal - Unesp (FCAVJ-Unesp), via de acesso Paulo Donato Castellane s/n, Jaboticabal, SP 14870-000.

${ }^{4}$ Seção de Bacteriologia do Instituto Adolfo Lutz, Av. Dr. Arnaldo 355, 012467-902 São Paulo, SP.

${ }^{5}$ Depto Medicina Veterinária Preventiva da FCAVJ/Unesp.
}

\section{INTRODUÇÃO}

As salmonelas estão amplamente difundidas na natureza e são capazes de infectar o homem e os animais. As aves acometidas por salmonelas paratíficas podem desenvolver a doença clinicamente ou de forma assintomática, albergar esses agentes, tornando-se fonte em potencial de salmonelose para seres humanos (Nagaraja et al. 1991, Barrow 1993).

Os casos de toxinfecções alimentares causados por Salmonella aumentaram a partir da década de 80. Rodrigue et al. (1990) atribuíram esse aumento ao consumo de ovos e subprodutos contaminados por Salmonella Enteritidis. Todavia, a presença de Salmonella em carcaças de frangos não pode ser ignorada (Rampling et al. 1989, Boer \& Zee 1992, Giessen et al. 1992, Poppe 1994, Scuderi et al. 1996, Costa 1996, Sakai \& Chalermchaikit 1996, Ward \& Threlfall 1997).

$\mathrm{Na}$ Inglaterra e País de Gales, a carne de frango foi responsável por surtos e casos esporádicos (Rampling et al. 1989) e por aproximadamente 30.000 casos/ano de toxinfecção alimentar em seres humanos (Ward \& Threlfall 1997). No Brasil, Tavechio et al. (1996) reportaram um aumento do isolamento de Salmonella Enteritidis a partir de 1993. Na Itália, de 1991 a 1994, dos 1699 surtos de origem alimentar, Salmonella foi responsável por $81 \%$, dos quais 34\% foram Salmonella Enteritidis (Scuderi et al. 1996). 
Os produtos de origem animal, principalmente avícolas, são considerados uma importante fonte de proteína humana. No comércio brasileiro, as carcaças podem ser encontradas na forma resfriada e congelada. $O$ resfriamento não inviabiliza a presença de bactérias como as do gênero Salmonella. Contudo, quando se trata do congelamento espera-se a redução ou ausência de células bacterianas viáveis. Forster \& Mead (1976) verificaram que salmonelas em carne de frango são destruídas mais rapidamente em temperaturas entre -2 e $-5^{\circ} \mathrm{C}$. Entretanto, a presença de Salmonella em amostras de carcaças de frango congeladas obtidas no comércio varejista da Inglaterra, em três estudos realizados por Watson \& Brown (1975) foi de $24,4 \%, 13,0 \%$ e $14,8 \%$; em Portugal, Bernardo \& Machado (1989) mostraram 60,5\% de positividade; nos Estados Unidos, Izat et al. (1991) obtiveram uma variação de 17 a $50 \%$ em três marcas comerciais analisadas; no comércio varejista da Índia foi de 9,2\% (Sharma 1992); e no Reino Unido o percentual encontrado foi de $80 \%$ (Roberts 1982).

No Brasil, não há relatos sobre a pesquisa de Salmonella em carcaças de frango congeladas. Considerando-se que grande parte da comercialização dá-se com carcaças congeladas, o conhecimento microbiológico das mesmas, no que concerne a microrganismos do gênero Salmonella, seria de extrema utilidade para avaliar a participação destas na disseminação de Salmonella. Desse modo, realizou-se o presente trabalho com o objetivo de investigar a presença de Salmonella em carcaças de frango congeladas.

\section{MATERIAL E MÉTODOS}

\section{Amostras examinadas}

Pesquisou-se a presença de Salmonella em 150 carcaças de frango congeladas, de quatro marcas comerciais obtidas no comércio varejista de Jaboticabal, São Paulo. Foram colhidas 43 amostras referentes a cada uma das marca $A, B$ e $D$, enquanto da marca $C$ foram colhidas 21 . As amostras eram levadas ao laboratório em sua embalagem de origem para posterior análise microbiológica. $\mathrm{O}$ procedimento experimental seguiu as recomendações de Flowers et al. (1992), com algumas modificações.

\section{Isolamento de Salmonella nas carcaças}

No laboratório a carcaça era mantida em temperatura de geladeira $\left(4\right.$ a $\left.6^{\circ} \mathrm{C}\right)$ durante 24 horas. Em seguida, colocava-se dentro de saco de polietilieno esterilizado e adicionavam-se $300 \mathrm{~mL}$ de água peptonada tamponada a $0,1 \%$. Realizava-se o processo de enxaguadura na carcaça (Cox et al. 1978), transferindo a solução obtida para um frasco de vidro. Após 6 horas em temperatura ambiente, o frasco era incubado a $43^{\circ} \mathrm{C}$ por mais 18 horas. Após as 24 horas, inóculos de $2 \mathrm{~mL}$ eram retirados e semeados em tubos contendo $20 \mathrm{~mL}$ dos caldos selenito-novobiocina, tetrationatonovobiocina e Rappaport-novobiocina, que eram incubados a $43^{\circ} \mathrm{C}$ por 24 horas. As culturas em enriquecimento seletivo eram semeadas em placas contendo ágar verde brilhante e ágar de Mac Conkey e depois eram incubadas a $43^{\circ} \mathrm{C}$ por 24 horas. As colônias apresentando perfil bioquímico do gênero Salmonella eram inoculadas no meio de diagnóstico presuntivo ágar tríplice açúcar ferro (TSI) e caldo lisina e incubadas a $37^{\circ} \mathrm{C}$ por 24 horas. A partir do ágar TSI, as colônias compatíveis com o gênero Salmonella eram semeadas em ágar triptose e incubava-se a $43^{\circ} \mathrm{C}$ por 24 horas. Posteriormente, realizavam-se as provas sorológicas com soros polivalentes anti-antígenos somáticos e flagelares de Salmonella. As amostras que permaneciam compatíveis com o gênero Salmonella eram enviadas ao Setor de Enterobactérias do Instituto Adolfo Lutz de São Paulo para tipagem.

\section{Antibiograma}

As cepas de Salmonella isoladas foram submetidas a testes de sensibilidade, conforme técnica de Kirby-Bauer (Bauer et al. 1966), com a utilização de discos impregnados com os seguintes antibióticos: gentamicina $(10 \mathrm{mcg})$, netilmicina $(30 \mathrm{mcg})$, aztreonam (30 mcg), cloranfenicol (30 mcg), tetraciclina (30 mcg), amicacina $(30 \mathrm{mcg})$, cefalotina $(30 \mathrm{mcg})$, ampicilina $(10 \mathrm{mcg})$, tobramicina (10mcg), polimixina B (30UI), sulfazotrim ( $25 \mathrm{mcg}$ ) e cefoxitina (30mcg)

\section{RESULTADOS}

De acordo com o Quadro 1, salmonelas foram isoladas em $32,0 \%$ das amostras examinadas, e os percentuais referentes às marcas $A, B, C$ e $D$ foram de $16,3 \%, 53,5 \%, 42,9 \%$ e $20,9 \%$, respectivamente. Detectaram-se entre as 48 cepas isoladas 11 sorotipos, os quais estão registrados no Quadro 2 . Os dados contidos no Quadro 3 mostram o comportamento das cepas frente à ação de agentes antimicrobianos.

Quadro 1. Total, número e percentual de carcaças contaminadas por Salmonella conforme as quatro marcas comerciais obtidas no comércio varejista de Jaboticabal, SP, 1996-1997

\begin{tabular}{ccc}
\hline Marcas analisadas & Amostras positivas/Total & $\%$ \\
\hline A & $7 / 43$ & 16,3 \\
B & $23 / 43$ & 53,5 \\
C & $9 / 21$ & 42,9 \\
D & $9 / 43$ & 20,9 \\
Total & $48 / 150$ & 32,0
\end{tabular}

Quadro 2. Sorotipos de Salmonella isolados de carcaças de frango congeladas e sua freqüência nas diferentes marcas comerciais analisadas

\begin{tabular}{lccccc}
\hline \multirow{2}{*}{ Sorotipos } & \multicolumn{4}{c}{ Marcas analisadas } & \multirow{2}{*}{ No de cepas $^{\circ}$} \\
\cline { 2 - 5 } & A & B & C & D & $(\%)$ \\
\hline S. Agona & - & 02 & 01 & - & $03(6,2)$ \\
S. Anatum & - & 01 & - & - & $01(2,1)$ \\
S. Enteritidis & 07 & 16 & 02 & 04 & $29(60,4)$ \\
S. Hadar & - & - & 02 & - & $02(4,2)$ \\
S. Havana & - & - & 01 & - & $01(2,1)$ \\
S. Mbandaka & - & 02 & - & - & $02(4,2)$ \\
S. Montevideo & - & - & - & 01 & $01(2,1)$ \\
S. Ouakam & - & 01 & - & - & $01(2,1)$ \\
S. Poona & - & - & 03 & - & $03(6,2)$ \\
S. Schwarzengrund & - & 01 & - & 03 & $04(8,3)$ \\
S. I 4,5,12: - & - & - & - & 01 & $01(2,1)$ \\
Total & & & & & \\
& 07 & 23 & 09 & 09 & $48(100)$
\end{tabular}

\section{DISCUSSÃO E CONCLUSÕES}

Os surtos de salmonelose humana foram relatados pela primeira vez por Gaffky em 1880 (Corrêa \& Corrêa 1992) e predominavam os casos de infecção por Salmonella Typhi. Todavia, com a industrialização dos alimentos, surgiram as 
Quadro 3. Número e percentual de resistência a 12 antimicrobianos, apresentados pelas cepas de salmonelas isoladas de carcaças de frango congeladas adquiridas no comércio varejista, Jaboticabal, SP, 1996-1997

\begin{tabular}{|c|c|c|c|c|c|c|c|c|c|c|c|c|c|}
\hline \multirow[t]{2}{*}{ Sorotipos } & \multirow{2}{*}{$\begin{array}{l}\mathrm{N}^{\circ} \text { de } \\
\text { cepas }\end{array}$} & \multicolumn{11}{|c|}{ Agentes antimicrobianos } & \multirow[b]{2}{*}{$\mathrm{CX}$} \\
\hline & & GEN $^{\mathrm{a}}$ & NET & ATM & CLO & TET & A MI & $\mathrm{CF}$ & $\mathrm{AM}$ & TO & PO & ST & \\
\hline S. Agona & 3 & 1 & - & - & - & - & - & 2 & 3 & 2 & - & - & - \\
\hline S. Anatum & 1 & - & - & - & - & - & - & 1 & 1 & - & - & - & 1 \\
\hline$S$. Enteritidis & 29 & 1 & 1 & 1 & - & - & 1 & 22 & 29 & 9 & 3 & - & 13 \\
\hline S. Hadar & 2 & - & - & - & - & 2 & - & 2 & 2 & - & - & - & 2 \\
\hline S. Havana & 1 & - & - & - & - & - & - & 1 & 1 & - & - & - & 1 \\
\hline S. Mbandaka & 2 & - & - & - & - & - & - & 2 & 2 & - & - & - & 2 \\
\hline S. Montevideo & 1 & - & - & - & - & - & - & - & 1 & - & - & - & - \\
\hline S. Ouakam & 1 & - & - & - & - & - & - & 1 & 1 & - & - & & 1 \\
\hline S. Poona & 3 & - & - & - & - & 1 & - & 3 & 3 & - & - & - & 3 \\
\hline S. Schwarzengrund & 4 & - & - & - & - & - & - & 1 & 4 & - & - & - & 1 \\
\hline S. I 4,5, 12: - & 1 & - & - & - & - & - & - & 1 & 1 & - & - & - & 1 \\
\hline Total & 48 & 2 & 1 & 1 & - & 3 & 1 & 36 & 48 & 11 & 3 & - & 25 \\
\hline$(\%)$ & 100,0 & 4,2 & 2,1 & 2,1 & & 6,2 & 2,1 & 75,0 & 100,0 & 22,9 & 6,2 & & 52,1 \\
\hline
\end{tabular}

${ }^{\mathrm{a}} \mathrm{GEN}=$ Gentamicina, NET $=$ Netilmicina, $\mathrm{ATM}=$ Aztreonam, $\mathrm{CLO}=$ Cloranfenicol, $\mathrm{TET}=$ Tetraciclina, $\mathrm{AMI}=\mathrm{Amicacina}, \mathrm{CF}=\mathrm{Cefalotina}, \mathrm{AM}=\mathrm{Ampicilina}, \mathrm{TO}=$ Tobramicina, $\mathrm{PO}=$ Polimixina $\mathrm{B}, \mathrm{ST}=$ Sulfazotrim, $\mathrm{CX}=$ Cefoxitina.

toxinfecções alimentares em função dos alimentos produzidos serem provenientes de animais criados em sistema intensivo (Tietjen \& Fung 1995). O sistema de produção e abate de frangos favorece a presença de Salmonella no produto final (Berchieri et al. 1987, 1989). O congelamento da carcaça tende a reduzir ou prejudicar a sobrevivência de enterobactérias (Forster \& Mead 1976). No Brasil, as carcaças de frango são comercializadas nas formas resfriada e congelada. Trabalho recente demonstrou que o percentual de carcaças resfriadas contaminadas por Salmonella é elevado (Costa et al. 1996). Contudo não há referência sobre carcaças congeladas.

O percentual médio de contaminação observado nas amostras foi de 32,0\% (Quadro 1). Esse valor está acima daqueles descritos por Watson \& Brown (1975) e Sharma (1992), que encontraram $24,4 \%, 13,0 \%, 14,8 \%$ e 9,21 , respectivamente. A literatura, também, apresenta relatos de níveis de contaminação superiores aos encontrados nesta pesquisa como aqueles descritos por Bernardo \& Machado (1989) que encontraram $60,5 \%$ e $46,9 \%$ em carcaças congeladas e refrigeradas, respectivamente, e Roberts (1982) que observou um percentual de $80 \%$ nas carcaças congeladas. A análise conjunta desses resultados indica que a carcaça de frango, mesmo congelada, pode veicular Salmonella para seres humanos.

Os valores encontrados para cada marca comercial diferiram entre si. Tal fato corrobora os resultados de Izat et al. (1991). A variação de resultados entre marcas comerciais pesquisadas sugere que a qualidade dos programas de higiene das granjas e incubatórios, assim como a qualidade dos abatedouros, embora em graus variados, ainda está aquém dos parâmetros desejados. Esse aspecto é digno de nota, pois a partir dos anos 80, nos países do primeiro mundo (Rodrigue et al. 1990), e na América Central e Sul, a partir dos anos 90 (Navarro et al. 1995), o número de casos de toxinfecção alimentar em seres humanos aumentou consideravelmente, devendo-se ao sorotipo $S$. Enteritidis, sendo que as aves são consideradas a principal fonte de contaminação. Em adição,
Lister (1988) demonstraram que a via vertical aparece como provável meio de introdução desse sorotipo em granjas de corte e que uma vez contaminada a granja, mesmo após a desinfecção a bactéria aparece nos novos lotes (Davies \& Wray 1995).

O Quadro 2 apresenta o número e percentual dos 11 sorotipos isolados de Salmonella. Com exceção de S. Ouakam, os demais já foram descritos como agente de toxinfecção alimentar em seres humanos (Rampling et al. 1989, Scuderi et al. 1996, Ward \& Threlfall 1997). Salmonella Enteritidis foi o sorotipo predominante, sendo isolado em 29 carcaças de 48 contaminadas. Esses dados estão de acordo com os dados internacionais (Rodrigue et al. 1990) e confirmam o alastramento desse sorotipo no Brasil conforme relatam Tavechio et al. (1996) e Taunay et al. (1996), em cujos trabalhos observa-se que até 1990 eram raros os isolamentos de Salmonella Enteritidis e depois passaram a predominar de forma consistente. Os achados desta pesquisa demonstraram a participação de alimento de origem aviária como veiculador desta salmonela.

Os achados encontrados no antibiograma, registrados na Quadro 3, diferiram daqueles observados por Berchieri Jr. (1983), que demonstrou resistência total ao sulfazotrim e resistência parcial à tetraciclina $(77,0 \%)$ e à cefoxitina $(0,7 \%)$; Bokanyi Jr. et al. 1990 encontraram o percentual de 3,6\% de resistência à ampicilina e 34,5\% à tetraciclina, Costa (1996) encontrou $3,79 \%$ de resistência à cefoxitina e $16,45 \%$ à tetraciclina. No entanto, estão em concordância com Bokanyl Jr. et al. (1990), Lee et al. (1993) e Nascimento et al. (1997) em relação à sensibilidade total ao cloranfenicol, e também Hadad \& Jemel (1990), Pohl et al. (1991) e Lee et al. (1993) quanto à resistência total à ampicilina.

Esses resultados servem de alerta, pois o uso indiscriminado de antibióticos no tratamento de infecções e a adição em rações animais como promotores de crescimento têm contribuído para a emergência de resistência entre cepas de Salmonella e outras bactérias (Berchieri Jr \& Barrow 1998) e 
estas podem estar presentes nos alimentos de origem animal e causar graves infecções em seres humanos. Pelos resultados do Quadro 3, apenas o cloranfenicol e o sulfazotrim poderiam ser empregados em terapêutica veterinária, pois as cepas testadas foram sensíveis a esses antimicrobianos.

Agradecimentos: Às Instituições FAPESP, CNPq e CAPES pelo auxílio financeiro e aos funcionários Sr. Antonio Jose dos Santos e D. Aparecida Rodrigues Baptista pela ajuda na parte experimental.

\section{REFERÊNCIAS}

Barrow P.A. 1993. Salmonella - present, past and future. Avian Pathol. 22:651669.

Bauer A.W., Kirby W.M.M., Sherris J.C. \& Turck M. 1964. Antibiotic susceptibility testing by a standardized single disk method. Am. J. Clin. Pathol. 45(4):493496.

Berchieri Jr. A. 1983. Contaminação por Salmonella em farinhas de origem animal utilizadas no preparo de rações. Dissertação de Mestrado, Instituto de Ciências Biomédicas, USP, São Paulo. 83p.

Berchieri Jr. A., Paulillo A.C., Rossi Jr. O.D., Irino K., Fernandes S.A., Ávila F.A., Pessôa G.V.A. \& Calzada C.T. 1987. Salmonella em um abatedouro avícola. Ars Vet. 3(1):81-87.

Berchieri Jr. A., Adachi S.Y., Calzada C.T., Paulillo A.C., Schoken-Iturrino R.P. \& Tavechio A.T. 1989. Farinha de carne como fonte de Salmonella em granja avícola. Pesq. Vet. Bras. 9:9-12.

Berchieri Jr. A. \& Barrow P.A. 1998. O desenvolvimento da microbiota intestinal em pintos de corte: prós e contras, p. 183-190. In: Conferência Apinco 1998 de Ciência e Tecnologia Avícolas. Campinas, São Paulo.

Bernardo F.M.A. \& Machado J.C.C. 1989. Prevalência de Salmonella em carcaças de frango em Portugal. Perspectiva epidemiológica em humanos. Revta Port. Ciênc. Vet. 84(489):31-45.

Boer E. \& Zee H.V. 1992. Salmonella in foods of animal origin in the Netherlands, p. 265-271. In: Salmonella and Salmonellosis Symposium, Ploufragan, França.

Bokanyi Jr., R.P., Stephens J.F. \& Foster D.N. 1990. Isolation and characterization of Salmonella from broiler carcasses or parts. Poult. Sci. 69:592-598.

Corrêa W.M. \& Corrêa C.M. 1992. Paratifos em geral, p. 167-174. In: Enfermidades Infecciosas dos Mamíferos Domésticos. $2^{\underline{a}}$ ed. MEDSI, Rio de Janeiro.

Costa F.N. 1996. Sorotipos de Salmonella em carcaças e cortes de frango obtidos na indústria e no comércio e comportamento das cepas isoladas frente à ação de antimicrobianos. Dissertação de Mestrado, Faculdade de Ciências Agrárias e Veterinárias, Unesp-Jaboticabal, SP. 71p.

Cox N.A., Mercuri A.J., Tanner D.A., Carson M.O., Thomson J.E. \& Bailey J.S. 1978. Effectiveness of sampling methods for Salmonella detection on processed broilers. J. Food Prot. 41:341-343.

Davies R.H. \& Wray C. 1995. Observações on disinfection regimens used on Salmonella enteritidis infected poultry units. Poult. Sci. 74:638-647.

Flowers R.S., D’Aoust J., Andrews W.H. \& Bailey J.S. 1992. Salmonella, p. 371422 In: Vanderzant C. \& Splittstoesser D.F. (ed.) Compendium of Methods for the Microbiological Examination of Foods. 3rd ed. American Public Health Association, Washington, USA.

Forster R.D. \& Mead G.C. 1976. Effect of temperature and added polyphosphate on the survival of salmonellae in poultry meat during cold storage. J. Appl. Bacteriol. 41:504-510.
Giessen A.W., Dufrenne J.B., Ritmeester W.S., Berkers P.A.T.A., Leeuwen W.J. \& Notermans S.H.W. 1992. The identification of Salmonella enteritidis-infected poultry flocks associated with an outbreak of human salmonellosis. Epidemiol. Infect. 109:405-411.

Hadad J.J. \& Jemel A. 1990. Antimicrobial resistence among Salmonellae from animals. Vet. Med. J. Giza. 38(1):35-43.

Izat A.L., Kopek J.M. \& Mcginnis J.D. 1991. Research note: incidence, number and serotypes of Salmonella on frozen broiler chickens at retail. Poult. Sci. 70:1438-1440.

Lee A.L., Threatt V.L., Puhr N.D., Levine P., Ferris K. \& Tauxe R.V. 1993. Antimicrobial resistant Salmonella spp isolated from healthy broiler chickens after slaughter. J. Am. Vet. Med. Assoc. 202(5):752-755.

Lister S.A. 1988. Salmonella enteritidis in broilers and broiler breedrs. Vet. Rec. 123:350.

Nagaraja K.V., Pomeroy B.S. \& Williams J.E. 1991. Paratyphoid infections, p. 99-130. In: Calnek et al. (eds.) Diseases of Poultry. 9th ed. Iowa State University Press, Ames, USA.

Nascimento V.P., Cardoso M.O., Ribeiro A.R., Santos L.R., Silva A.B., Pontes A.P. \& Oliveira S.D. 1997. Prevalência e perfis de resistência de Salmonella isoladas de carcaças de frango frente a antimicrobianos e desinfetantes selecionados, p. 291 In: XIX Congresso Brasileiro de Microbiologia, Rio de Janeiro.

Navarro M.P. 1995. Infecção por Salmonella enteritidis em reprodutoras pesadas na América Latina, p. 7-16. In: Conferência Apinco 1995 de Ciência e Tecnologia Avícolas, Curitiba, Paraná.

Pohl P., Lintermans P., Marin M. \& Couturier M. 1991. Epidemiological study of Salmonella enteritidis strains of animal origin in Belgium. Epidemiol. Infect. 106:11-16.

Poppe C. 1994. Salmonella enteritidis in Canada. Int. J. Food Microbiol. 21:1-5.

Rampling A., Upson R., Peters E., Anderson J.R., Ward L.R. \& Rowe B. 1989. Salmonella enteritidis phage type 4 infection of broiler chickens: a hazard to public health. Lancet 14:436-438.

Roberts T. 1982. Factors contributing to outbreaks of food poisoning in England and Wales 1970-1979. J. Hyg. 89:491-498.

Rodrigue D.C., Tauxe R.V. \& Rowe B. 1990. International increase in Salmonella enteritidis: a new pandemic? Epidemiol. Infect. 105:21-27.

Sakai T. \& Chalermchaikit T. 1996. The major sources of Salmonella enteritidis in Thailand. Int. J. Food Microbiol. 31:173-180.

Scuderi G., Fantasia M., Filetici E. \& Anastasio M.P. 1996. Foodborne outbreaks caused by salmonella in Italy, 1991-1994. Epidemiol. Infect.116:257-265.

Sharma V. D. 1992. Salmonella contamination of foods of animal origin, p.137138. In: Salmonella and Salmonellosis Symposium, Ploufragan, França.

Tavechio A.T., Fernandes, S.A., Neves, B.C., Dias, A.M.G. \& Irino. K. 1996. Changing patterns of Salmonella serovars: increase of Salmonella Enteritidis in São Paulo, Brazil. Revta Inst. Med. Trop. 38(5):315-332.

Taunay A.E., Fernandes S.A., Tavechio A.T., Neves B.C., Dias A.M.G. \& Irino K. 1996. The role of public health laboraty in the problem of salmonellosis in São Paulo, Brazil. Revta Inst. Med. Trop. 38(2):119-127.

Tietjen M. \& Fung D.Y.C. 1995. Salmonellae and food safety. Crit. Rev. Microbiol. 21(1):53-83.

Ward L.R. \& Threlfall E.J. 1997. Human salmonellosis in England and Wales current situation, p. 547-9. In: Salmonella and Salmonellosis Symposium, Ploufragan, França.

Watson W.A. \& Brown J.M. 1975. Salmonella infection and meat hygiene: poultry meat. Vet. Rec. 96:351-353. 